\title{
Forty years after the first totally implantable venous access device (TIVAD) implant: the pure surgical cut-down technique only avoids immediate complications that can be fatal
}

\author{
Adriana Toro $^{1} \cdot$ Elena Schembari $^{2} \cdot$ Emanuele Gaspare Fontana $^{3} \cdot$ Salomone Di Saverio $^{4,5} \cdot$ Isidoro Di Carlo $^{3}$
}

Received: 18 May 2021 / Accepted: 1 June 2021 / Published online: 9 June 2021

(c) The Author(s) 2021

\begin{abstract}
Aim Even though TIVADs have been implanted for a long time, immediate complications are still occurring. The aim of this work was to review different techniques of placing TIVAD implants to evaluate the aetiology of immediate complications. Methods A systematic literature review was performed using the PubMed, Cochrane and Google Scholar databases in accordance with the PRISMA guidelines. The patient numbers, number of implanted devices, specialists involved, implant techniques, implant sites and immediate complication onsets were studied.

Results Of the 1256 manuscripts reviewed, 36 were eligible for inclusion in the study, for a total of 17,388 patients with equivalent TIVAD implantation. A total of 2745 patients (15.8\%) were treated with a surgical technique and 14,643 patients $(84.2 \%)$ were treated with a percutaneous technique. Of the 2745 devices (15.8\%) implanted by a surgical technique, 1721 devices (62.7\%) were placed in the cephalic vein (CFV). Of the 14,643 implants (84.2\%) placed with a percutaneous technique, 5784 devices (39.5\%) were placed in the internal jugular vein (IJV), and 5321 devices (36.3\%) were placed in the subclavian vein (SCV). The number of immediate complications in patients undergoing surgical techniques was $32(1.2 \%)$ HMMs. In patients treated with a percutaneous technique, the number of total complications were 333 (2.8\%): 71 PNX $(0.5 \%), 2$ HMT $(0.01 \%), 175$ accidental artery punctures AAP (1.2\%) and 85 HMM (0.6\%). No mortality was reported with either technique.

Conclusion The percutaneous approach is currently the most commonly used technique to implant a TIVAD, but despite specialist's best efforts, immediate complications are still occurring. Surgical cut-down, 40 years after the first implant, is still the only technique that can avoid all of the immediate complications that can be fatal.
\end{abstract}

Keywords Totally implantable venous access device (TIVAD) - Surgical cut-down · Percutaneous approach · Pneumothorax $\cdot$ Port-a-cath

Isidoro Di Carlo

idicarlo@unict.it

1 General Surgery, Augusta Hospital, Syracuse, Italy

2 Department of General Surgery, Whipps Cross University Hospital-Barts Health NHS Trust, Whipps Cross Rd, Leytonstone, , London E11 1NR, UK

3 Department of Surgical Sciences and Advanced Technologies "G.F. Ingrassia," Cannizzaro Hospital, General Surgery, University of Catania, Via Messina 829, 95126 Catania, Italy

4 Department of General Surgery, University Hospital of Varese, University of Insubria, Varese, Italy

5 Cambridge Colorectal Unit, Addenbrooke's University Hospital NHS Foundation Trust, Cambridge, UK

\section{Introduction}

In 1980, Dr. John Niederhuber realized an idea when faced with a family situation. His wife, who was affected by cancer, needed multiple venous infusions that progressively damaged the status of her veins. This inspired the invention of the totally implantable venous access device that was first manufactured by Pharmacia ${ }^{\circledR}$ [1]. Inspired by an act of love, this invention still represents a milestone for oncological patients. It mitigates the local toxicity of antineoplastic drugs, shortens the length of the infusions and undoubtedly improves the quality of life of the patients. In addition to patients with cancer, many categories of patients needing continuous venous catheterizations use these devices. Since the first implant, the Seldinger technique has been used for 
39 years [2], but Dr. Niederhuber chose a surgical technique using a small peripheral vein to place his catheter in the vena cava [3]. No percutaneous technique was utilized for the first 10 years, and no immediate lethal complications have been reported.

In the last 30 years, the percutaneous technique has spread worldwide to satisfy the increasingly numerous requests for TIVAD implants. In this way, many physicians, not surgeons, such as anaesthesiologists and radiologists, have applied the easiest and most available Seldinger technique to perform TIVAD implantation. This technique, which usually does not need an operating room, has the disadvantage of immediate complications, such as pneumothorax, haemopneumothorax, arterial puncture and haematoma. Despite these risks, the incessant requests over the years have made the percutaneous technique the technique of choice rather than surgical cut-down. In association with the massive diffusion of percutaneous techniques worldwide, its related complications have also become well-known [4]. Some of these complications are particularly dangerous because they could cause patient death [4].

To reduce the complications of the percutaneous approach during recent decades, many attempts have been made, and the exact identification of the location of the vein before puncture using ultrasound (US) landmark blinding is the most commonly used method [5]. In recent years, improvement of this technique has resulted in real-time ultrasound guidance [6]. However, despite the technological assistance, immediate complications continue to be reported in the literature and reduce the quality of life of the patients, who are usually already sick and fragile [7].

The aim of this work was to explore the progress in relation to all immediate complications following different techniques adopted for placing TIVAD implants in the last 10 years. We limited this study to the last 10 years because in our previous study [8], we evaluated the immediate complications associated with the surgical cut-down and percutaneous approach technique between the first implant and 2010 .

\section{Methods}

A systematic literature review was performed using the PubMed, Cochrane and Google Scholar databases, in accordance with the PRISMA guidelines [9] to identify published studies from January 2010 through April 2021.

The keywords used for the search were "totally implantable venous access device", "totally implantable venous access port", "port-a-cath", "percutaneous technique", "cutdown technique" and "immediate complications". These keywords were used individually or with the help of the Boolean operator "AND".
All abstracts were read. Case reports, letters, comments, articles not written in the English language and articles on animals were excluded. Articles analysing adult patients with a TIVAD and immediate complications were considered for full-text review.

We collected articles showing the patient number, number of implanted devices, specialists involved (surgeons (general surgeons, vascular surgeons, thoracic surgeons and cardiovascular surgeons) and other specialists (interventional radiologists, anaesthetists, oncologists, etc.)), the implant technique (surgical or percutaneous technique) and the site of the implant, and the onset of immediate complications such as pneumothorax (PNX), haemothorax (HTM), accidental arterial puncture (AAP), and haematoma (HMM). Finally, we searched for ultrasound (US) use during implantation and the related complications recorded with this approach. Sex, age, type of anaesthesia and device characteristics were not considered for the present study because they did not influence the research and consequently did not influence the results. Documents that clearly did not meet the inclusion criteria were excluded at this stage.

Complications are defined as "immediate" if they occur during the first $24 \mathrm{~h}$ after implant placement. Related mortality was investigated.

\section{Results}

A total of 1256 manuscripts were examined. After reviewing all of the abstracts, 1148 articles were excluded for not meeting the inclusion criteria. Among the remaining 108 manuscripts, the following were excluded after full-text review: 26 studies because they did not analyse complications; 19 analysed only late complications; 11 used implant sites not compatible with the study; 7 analysed only one type of late complication; 7 were case reports, letters to the editor or a comment; and 1 only analysed paediatric patients (Fig. 1).

Finally, only 37 articles met all of the inclusion criteria and were used for the present study. These manuscripts were published between January 2010 and February 2021.

A total of 17,496 patients received the equivalent number of TIVAD implants, and they were analysed. Of these, 2853 patients $(16.3 \%)$ were treated with a surgical technique, and 14,643 patients $(83.7 \%)$ were treated with a percutaneous technique (Tables 1, 2 and 3) [10-46].

Of the 37 manuscripts examined, 15 articles reported the TIVADs were implanted by surgeons, and in 4 of these manuscripts, residents were also involved in the procedures. In 10 manuscripts, the TIVADs were implanted by other physicians (not surgeons), and in 3 of these 10 articles, residents were involved in the procedure. In 11 manuscripts, the physicians that performed the procedure were not specified. Finally, 1 article reported that both surgeons and radiologists 
Fig. 1 Algorithm used to screen the literature

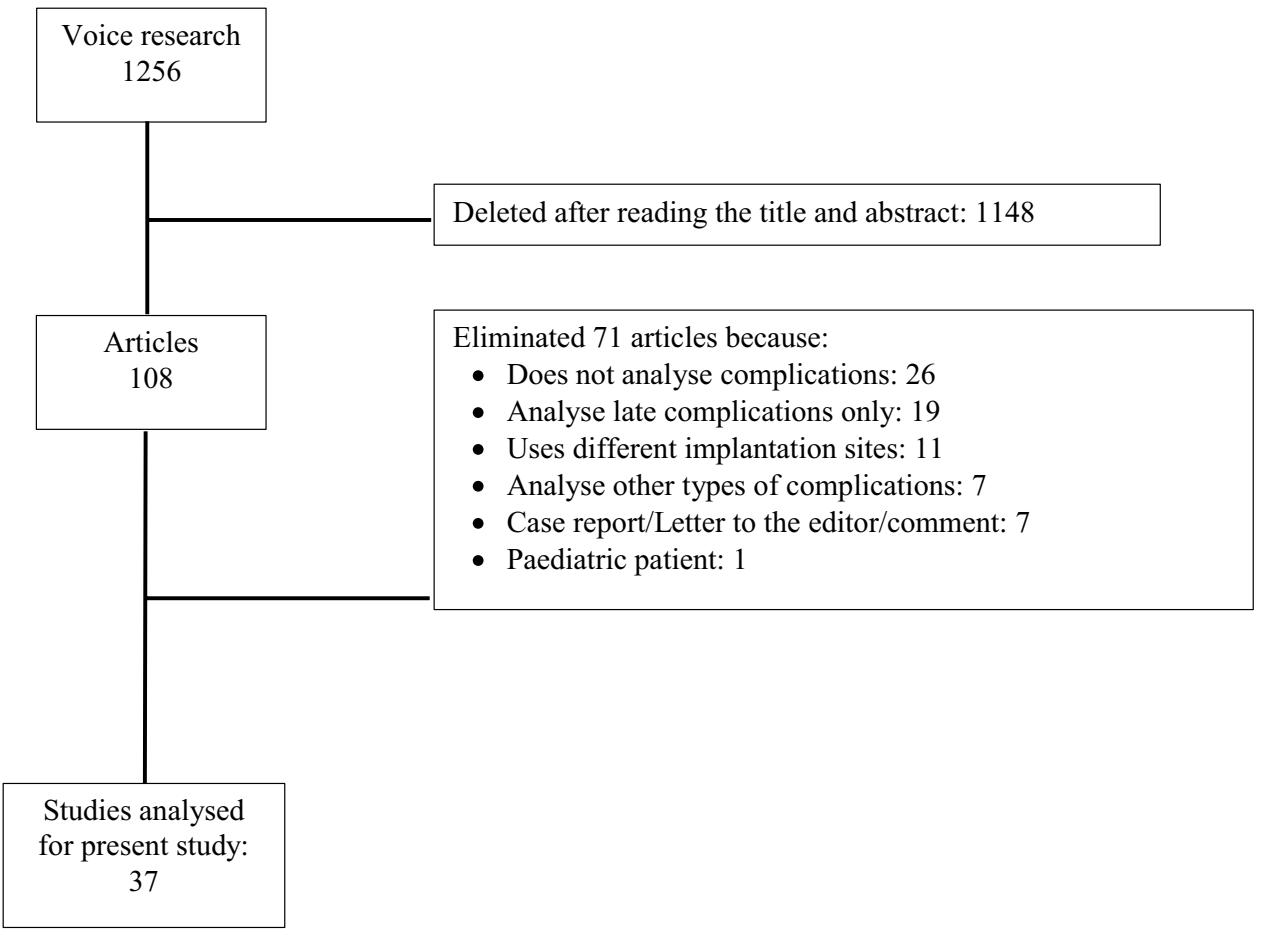

performed the procedures. Considering the number of techniques performed in relation to the manuscripts, in the first 14 articles, 8210 procedures were reported, of which 2243 (27.3\%) were performed using the cut-down technique and $5967(72.7 \%)$ with percutaneous techniques. In the second group of 10 manuscripts, all 3743 implants were performed percutaneously by physicians (not surgeons). In the 11 manuscripts in which the kind of physicians performing the procedure were not clearly indicated, a total of 5441 implants were reported; of these, 557 (10.2\%) were performed with surgical cut-down techniques, and 4884 (89.8\%) were performed by percutaneous techniques. Finally, 1 manuscript reported a total of 102 patients treated by radiologists in 49 cases $(48.0 \%)$ by the percutaneous approach and in 53 cases $(52.0 \%)$ by surgeons using the cut-down technique (Table 4$)$.

Concerning the technique used in the 37 manuscripts, in 7 manuscripts (18.9\%), surgical cut-down was reported, the percutaneous technique was reported in 23 articles (62.2\%), and both techniques were described in 7 articles (18.9\%). No US was used in the first 7 studies in which TIVAD was implanted with the pure cut-down technique. In the second group of studies, of the 12,399 patients undergoing percutaneous US, the vein was cannulated in 6636 patients $(53.5 \%)$, while in 5763 patients $(46.5 \%)$, the vein was punctured using anatomical blind landmarks.

Finally, in the third group of 7 manuscripts in which 2954 patients were treated with both techniques, the cutdown technique was used for 710 patients $(23.8 \%)$, while the percutaneous technique was used for 2244 patients (76.2\%). Among all of these patients, 1333 underwent US; for patients submitted to surgical techniques, the vein was located with US in 352/1333 patients (26.4\%), while in the percutaneous technique group, the vein was localized by US in $981 / 1333$ patients $(73.6 \%$ ) (Table 5). In the last two groups of manuscripts (23 manuscripts percutaneous only and 7 manuscripts with cut-down only), patients for whom the approach did not include US experienced 60 PNX $(0.5 \%)$ in contrast to the patients in which the TIVAD was placed using US where 11 PNX were reported (0.09\%) (Table 6).

Of the 2853 devices (16.3\%) implanted by a surgical technique, 1822 devices $(63.9 \%)$ were placed in the cephalic vein (CFV), 963 devices $(33.8 \%)$ in the external jugular vein (EJV) and 68 devices $(2.4 \%)$ in the brachiocephalic vein (BCV). Of the 14,643 implants $(83.7 \%)$ placed with a percutaneous technique, 5784 devices $(39.5 \%)$ were placed in the internal jugular vein (IJV), 5321 devices (36.3\%) were placed in the subclavian vein (SCV), 2172 devices (14.8\%) were placed in the axillary vein (AXV), 744 devices $(5.1 \%)$ were placed in the innominate vein (INV) and 622 devices $(4.2 \%)$ were placed in the brachiocephalic vein (BCV) (Table 7).

Immediate complications in patients undergoing surgical techniques were $32(1.1 \%)$ HMMs. In patients treated with a percutaneous technique, the total complications were 333 (2.8\%): 71 PNX (0.5\%), 2 HMT (0.01\%), 175 AAP (1.2\%) and $85 \mathrm{HMM}(0.6 \%)$.

No mortality was reported with either technique (Tables 8 and 9).

There were 365 complications overall. In 10 articles (27.1\%), there were 200 complications (54.8\%), but they 

analysed in the present manuscript. Some of these studies [3, 9, 10, 13, 21, 22, 28] reported that surgical cut-down was a percutaneous approach. For this reason, a manuscript with related techniques can be listed in more than one table
Table 1 All manuscripts

\begin{tabular}{ll}
\hline Year & Author \\
\hline 2010 & Silas [10] \\
2010 & Koketsu [11] \\
2011 & Knebel [12] \\
2011 & Lin [13] \\
2011 & Barbetakis [14] \\
2011 & Di Carlo [15] \\
2011 & Narducci [16] \\
2012 & Kim [17] \\
2013 & Osawa [18] \\
2015 & Lin [19] \\
2014 & Cavallaro [20] \\
2014 & Cheng [21] \\
2014 & Zhou [22] \\
2014 & Granziera [23] \\
2014 & Cavallaro [24] \\
2014 & Seo [25] \\
2015 & Tagliari [26] \\
2015 & Gurkan [27] \\
2015 & An [28] \\
2015 & Wu [29] \\
2015 & Cavallaro [30] \\
2016 & Otsubo [31] \\
2016 & Zerati [32] \\
2016 & Ma [33] \\
2017 & Feo [34] \\
2017 & Seo [35] \\
2017 & Kagawa [36] \\
2018 & Hong [37] \\
2019 & Hashimoto [38] \\
2019 & Sun [39] \\
2019 & Xu [40] \\
2019 & Sun [41] \\
2019 & Sun [42] \\
2019 & Velioglu [43] \\
Souadka [44] & Mehta [45] \\
Sun [46] \\
\hline
\end{tabular}

were not reported by the implantation site. In the remaining 27 articles (72.9\%), it was possible to divide the complications by the implant site for a total of 165 complications (45.2\%). With the surgical technique, HMM complications of TIVAD implantation were observed in the CFV $1(0.1 \%)$, and there were cases of HMM after implantation in the EJV $4(0.3 \%)$. With the percutaneous technique, the complications of TIVAD implantation in the IJV were 2 PNX $(0.03 \%), 15 \mathrm{APA}(0.3 \%)$ and $5 \mathrm{HMM}(0.09 \%)$; with the SCV technique, the complications were $26 \mathrm{PNX}(0.5 \%), 68 \mathrm{APA}$ (1.3\%) and $29 \mathrm{HMM}(0.5 \%)$; with the AXV technique, the complications were 6 PNX $(0.3 \%)$ and 5 APA $(0.2 \%)$; with
Table 2 Manuscripts with surgical procedures

\begin{tabular}{llll}
\hline Year & Author & $\begin{array}{l}\text { Number } \\
\text { implanted }\end{array}$ & $\begin{array}{l}\text { Surgical } \\
\text { tech- } \\
\text { nique }\end{array}$ \\
\hline 2010 & Koketsu [11] & 74 & 74 \\
2011 & Knebel [12] & 53 & 53 \\
2011 & Di Carlo [15] & 108 & 108 \\
2011 & Narducci [16] & 771 & 771 \\
2015 & Lin [19] & 27 & 27 \\
2014 & Cavallaro [20] & 155 & 155 \\
2014 & Granziera [23] & 102 & 102 \\
2014 & Cavallaro [24] & 753 & 753 \\
2015 & Cavallaro [30] & 83 & 83 \\
2016 & Otsubo [31] & 149 & 149 \\
2016 & Zerati [32] & 21 & 21 \\
2017 & Kagawa [36] & 254 & 254 \\
2019 & Hashimoto [38] & 203 & 203 \\
2020 & Mehta [45] & 100 & 100 \\
& & 2853 & 2853 \\
\hline
\end{tabular}

the INV technique, the complications were 1 PNX $(0.1 \%)$, 5 APA $(0.7 \%)$ and 1 HMM $(0.1 \%)$; while with the CBV technique, there was 1 APA $(0.2 \%)$ (Table 10$)$.

\section{Discussion}

When TIVAD was patented and used for the first time, the Seldinger technique was used all over the world for almost four decades [2]. However, the surgeon who patented the TIVAD does not use the Seldinger technique to implant it, and he prefers to surgically isolate a small and relatively peripheral vein, the cephalic vein. What was the rationale of the inventor of this technique to choose a surgical cut-down instead of a percutaneous approach? The most important implication that must be considered for the first implants is that at that time, only oncological patients needed a TIVAD. These patients were particularly frail because they had already undergone multiple vein punctures and they had experienced the local toxicity of anticancer drugs [47]. The Seldinger technique is complicated by PNX and hemothorax, which can be lethal. This was very likely the rationale for the choice of surgical approach, avoiding as much suffering and possible complications related to the Seldinger technique, among patients who already have a compromised quality of life due to their cancer. This rationale, which most likely was taken into consideration by J H Niederhuber, still remains, despite the widespread use of the Seldinger technique and should be one of the main concerns about the technical choice for TIVAD implants [48]. 
Table 3 Manuscripts reporting a percutaneous technique

\begin{tabular}{|c|c|c|c|}
\hline Year & Author & Number implanted & $\begin{array}{l}\text { Percu- } \\
\text { taneous } \\
\text { technique }\end{array}$ \\
\hline 2010 & Silas [10] & 536 & 536 \\
\hline 2011 & Knebel [12] & 49 & 49 \\
\hline 2011 & Lin [13] & 113 & 113 \\
\hline 2011 & Barbetakis [14] & 700 & 700 \\
\hline 2012 & Kim [17] & 441 & 441 \\
\hline 2013 & Osawa [18] & 207 & 207 \\
\hline 2015 & Lin [19] & 29 & 29 \\
\hline 2014 & Cavallaro [20] & 143 & 143 \\
\hline 2014 & Cheng [21] & 214 & 214 \\
\hline 2014 & Zhou [22] & 492 & 492 \\
\hline 2014 & Granziera [23] & 690 & 690 \\
\hline 2014 & Seo [25] & 216 & 216 \\
\hline 2015 & Tagliari [26] & 110 & 110 \\
\hline 2015 & Gurkan [27] & 324 & 324 \\
\hline 2015 & An [28] & 397 & 397 \\
\hline 2015 & Wu [29] & 668 & 668 \\
\hline 2016 & Otsubo [31] & 122 & 122 \\
\hline 2016 & Zerati [32] & 1202 & 1202 \\
\hline 2016 & Ma [33] & 2996 & 2996 \\
\hline 2017 & Feo [34] & 527 & 527 \\
\hline 2017 & Seo [35] & 932 & 932 \\
\hline 2018 & Hong [37] & 176 & 176 \\
\hline 2019 & Hashimoto [38] & 9 & 9 \\
\hline 2019 & Sun [39] & 55 & 55 \\
\hline 2019 & $\mathrm{Xu}[40]$ & 67 & 67 \\
\hline 2019 & Sun [41] & 283 & 283 \\
\hline 2019 & Sun [42] & 619 & 619 \\
\hline 2019 & Velioglu [43] & 2084 & 2084 \\
\hline 2020 & Souadka [44] & 135 & 135 \\
\hline \multirow[t]{2}{*}{2021} & Sun [46] & 107 & 107 \\
\hline & & 14,643 & 14,643 \\
\hline
\end{tabular}

Over these 40 years, TIVAD has had great success around the world, and for several reasons (increases in indications for chemotherapeutic drug venous infusions, the inability of surgeons to satisfy massive requests for their placement, leading to an increased need for radiologists and anaesthesiology, etc.), and progressively, the cut-down technique has become less commonly used than the Seldinger technique. Unfortunately, the percutaneous approach has a risk of immediate complications, and if not coupled with US guidance, they can be serious or even lethal.

The Seldinger technique is an extremely useful venous line placement approach that is used in many fields of medicine. When it is used in cases of emergency or trauma, complications, especially PNX, can be justified because the procedure is being applied as an emergent lifesaving procedure. Different considerations arise when the patients needing the Seldinger approach are not in immediate danger and, as oncological patients, instead need a TIVAD placed avoid some complications related to chemotherapeutic drugs. In this last case, we have to guarantee better conditions, preserving the quality of life of these frail patients [49].

Despite these considerations in the last 10 years, the rate of immediate PNX related to the percutaneous approach is alarmingly high [8]. PNX, haemothorax and accidental puncture of arteries do not occur during the surgical techniques. Anatomical, landmark-based, "blind" percutaneous access for TIVAD implantation is associated with the majority of complications related to this percutaneous US technique. In contrast, when real-time ultrasound vein identification is used for vein cannulation, the results in terms of complications are improved. In fact, a $0.2 \%$ rate of PNX occurred when a systematic use of US guidance was chosen, compared with $1.0 \%$ of blind landmark percutaneous procedures (Table 6).

To preserve the safety of the surgical approach to the cephalic vein, a mixed technique has been described in the literature. These studies, excluded from the present study to avoid confusing data, are based on the possibility of using the Seldinger technique in part or in toto when the open cutdown fails. These techniques are associated with a nil PNX rate [50] and can be considered a valid rescue technique in cases of unusable cephalic veins. Another manuscript has reported cases of PNX after conversion from the cut-down to a percutaneous approach [51]. These studies, undoubtedly valid from the scientific point of view, are unacceptable for both patients who experience the complication and for
Table 4 Types of physicians doing the procedure

\begin{tabular}{llllrll}
\hline Physician & $\begin{array}{l}\text { Number } \\
\text { articles }\end{array}$ & $\begin{array}{l}\text { Articles with } \\
\text { residents }\end{array}$ & Number implanted & $\%$ & $\begin{array}{l}\text { Surgical } \\
\text { technique }\end{array}$ & $\begin{array}{l}\text { Percu- } \\
\text { taneous } \\
\text { technique }\end{array}$ \\
\hline Surgeon & 15 & 4 & 8210 & $46.9 \%$ & 2243 & 5967 \\
Other & 10 & 3 & 3743 & $21.4 \%$ & 0 & 3743 \\
Surgeon + other & 1 & - & 102 & $0.6 \%$ & 53 & 49 \\
Not reported & 11 & - & 5441 & $31.1 \%$ & 557 & 4884 \\
Total & 37 & 7 & 17,496 & $100.0 \%$ & 2853 & 14,643 \\
\hline
\end{tabular}


Table 5 Number of patients in which ultrasound (US) was used to exactly localize the vein. Not US indicates patients in which the vein (both surgical or percutaneous) has been approached using anatomical landmarks

\begin{tabular}{llllllrrr}
\hline & $\begin{array}{l}\text { Number } \\
\text { articles }\end{array}$ & Number implanted & $\begin{array}{l}\text { Surgical } \\
\text { technique }\end{array}$ & $\begin{array}{l}\text { Percutaneous } \\
\text { technique }\end{array}$ & US & Not US & $\%$ \\
\hline Surgical technique & 7 & 2143 & 2143 & & & & 2143 \\
Percutaneous technique & 23 & 12,399 & & 12,399 & 6636 & $53.5 \%$ & 5763 & $46.5 \%$ \\
Both techniques & 7 & 2954 & 710 & 2244 & 1333 & $45.1 \%$ & 1621 & $54.9 \%$ \\
& 37 & 17,496 & 2853 & 14,643 & 7969 & $45.8 \%$ & 9527 & $54.2 \%$ \\
\hline
\end{tabular}

Table 6 Patients submitted to the percutaneous approach with (US) and without (NUS) US vein localization and related PNX

\begin{tabular}{llr}
\hline $\begin{array}{l}\text { Percutane- } \\
\text { ous tech- } \\
\text { nique }\end{array}$ & 12,399 & \multicolumn{1}{l}{$\%$} \\
\hline US & 6636 & $53.5 \%$ \\
PNX & 11 & $0.2 \%$ \\
NUS & 5763 & $46.5 \%$ \\
PNX & 60 & $1.0 \%$ \\
\hline
\end{tabular}

Table 7 Sites of the TIVAD implant

\begin{tabular}{lllr}
\hline Total of implants 17,496 & & & \\
\hline Surgical procedure 2853 & CFV & 1822 & $63.9 \%$ \\
& EJV & 963 & $33.8 \%$ \\
& BCV & 68 & $2.4 \%$ \\
Percutaneous procedure 14,643 & & 2853 & $100.0 \%$ \\
& IJV & 5784 & $39.5 \%$ \\
& SCV & 5321 & $36.3 \%$ \\
& AXV & 2172 & $14.8 \%$ \\
& INV & 744 & $5.1 \%$ \\
& BCV & 622 & $4.2 \%$ \\
& & 14,643 & $100.0 \%$
\end{tabular}

Legend: $C F V$, cephalic vein; $E J V$, external jugular vein; $B C V$, brachiocephalic vein; $I J V$, internal jugular vein; $S C V$, subclavian vein; $A X V$, axillary vein; $I N V$, innominate vein

surgeons, who may have been able to finish the procedure with a risk-free surgical approach [52, 53].

Although the classical cut-down technique is safe, failure of cannulation of the cephalic vein can occur [51]. Seldinger's "blind" choice after an initial failure of the open technique must be absolutely avoided, and if clinicians want to use a percutaneous technique, US real-time guidance may be beneficial in such a situation. However, this revolutionary US technique does not fully prevent immediate complications.

Recently, another mixed technique has been reported [54]. In this manuscript, the authors report the complete surgical preparation of the internal jugular vein, and then after clamping, the catheter is inserted using the Seldinger technique through the venous wall. In this innovative procedure, however, there are 2 important complications to keep in mind: puncture of the carotid artery, which requires suturing, and the possibility of PNX. The focus of this manuscript is on immediate complications, but after preparation of the internal jugular vein, surgical insertion of the catheter may avoid these complications [54].

The best method to convert to in cases of failure of cephalic vein cut-down can be considered the technique of Knebel et al. [50]. In this case, the Seldinger technique is used in a hybrid form. In fact, the technique used involves introducing a guidewire into a stenotic vein and then tentatively dilating the same vein. If the procedure achieves its purpose, this represents the best method to complete the TIVAD implant without risk to the patients. In cases of failure of this technique, the direct Seldinger technique is not recommended and, instead, if the competencies of the physicians allow it, it is recommended to adopt real-time ultrasound vein cannulation. However, safety is only ensured by the surgical cut-down of another vein $[52,53]$.

TIVAD implantation is considered a simple procedure (both surgically and percutaneously), achievable by both senior residents and by surgeons. In the present study, manuscripts in which residents have been involved in both techniques have been reported. The rate of immediate complications with the percutaneous approach is near $0.05 \%$ [ 10 , $13,29]$. In contrast, for the cut-down technique, the complication rate is nil $[33,34,38]$. Therefore, residents will have better success when they practice the cut-down technique.

The technique that is currently being used the most worldwide is the percutaneous approach. The major cause of this preference is related to the increased requests for a TIVAD that cannot be met by surgeons. In fact, the surgical approach usually requires an operating room, nurses and surgeons dedicated to the procedure. In contrast, when the procedure is performed by a radiologist or anaesthesiologist, it may be performed in a radiological interventional room with only two persons (a radiologist and a nurse).

This decreases the cost and time needed for the procedure, as well as the patient's stress, who may think a procedure performed in an interventional radiological room is less risky and invasive than a procedure performed in 
Table 8 Immediate complications that occurred with pure surgical techniques by author and type of complication

\begin{tabular}{lllllll}
\hline Year & Author & $\begin{array}{l}\text { Surgical tech- } \\
\text { nique }\end{array}$ & PNX & HMT & APP & HMM \\
\hline 2010 & Koketsu [11] & 74 & - & - & - & - \\
2011 & Knebel [12] & 53 & - & - & - & 1 \\
2011 & Di Carlo [15] & 108 & - & - & - & - \\
2011 & Narducci [16] & 771 & - & - & - & 26 \\
2015 & Lin [19] & 27 & - & - & - & 1 \\
2014 & Cavallaro [20] & 155 & - & - & - & 1 \\
2014 & Granziera [23] & 102 & - & - & - & - \\
2014 & Cavallaro [24] & 753 & - & - & - & - \\
2015 & Cavallaro [30] & 83 & - & - & - & - \\
2016 & Otsubo [31] & 149 & - & - & - & - \\
2016 & Zerati [32] & 21 & - & - & - & - \\
2017 & Kagawa [36] & 254 & - & - & - & 3 \\
2019 & Hashimoto [38] & 203 & - & - & - & - \\
2020 & Mehta [45] & 100 & - & - & - & - \\
& & 2853 & & & & 32 \\
\hline
\end{tabular}

Legend: $P N X$, pneumothorax; $H M T$, haemothorax; $A A P$, accidental arterial puncture; $H M M$, haematomas an operation room. The same logistical situation can be related to the need for anaesthesiologists. These different situations have another consequence: the cost. The cost of a procedure and the related income are considered worldwide as one of the major factors to affect its acceptance by the administration, not only in nations where private/ insurance system exists but also in countries where the taxes of citizens maintain a public health system, such as in Europe. The costs of the percutaneous approach are much lower than the surgical cut-down approach, and in addition, operation rooms can be reserved for more profitable surgical procedures [46]. The effort to control costs is increasing in all health systems around the world, frequently not in accordance with the aspects of the disease and the related quality of life of the patients. This aspect should be carefully re-evaluated by putting oncological patients first as targets of the situation, considering their disease and related quality of life as the primary objective of the health system before any economic considerations [55].

In the present review, the different veins seemed to require different techniques, with the cephalic vein best handled with a surgical approach and the internal jugular vein best handled with a percutaneous approach. The absence of immediate life-threatening complications when using the cephalic vein is quite acceptable. The internal jugular vein has a lower rate of immediate complications than subclavian vein access. Landmarks for the IJV are more evident and intuitive in relation to the subclavian vein, which can probably explain the difference between the two techniques when approached using landmarks. This represents almost all cases.
To avoid the majority of complications related to the puncture technique in the last 10 years, ultrasound techniques have been increasingly used. The aim of these diagnostic tools should be to eliminate the immediate complications related to the Seldinger technique, improve the quality of life of the patients and finally also influence the cost of the procedure. However, even with identification of the morphological position by US, the rate of PNX has decreased but is still higher than that for cephalic vein cut-down. Many reasons can be considered: (a) resident involvement in the procedure, who is not sufficiently trained and skilled to safely finish the procedure; (b) not all procedures are carried out by residents, and for skilled radiologists or anaesthesiologists, poor conditions of the patients (for example, obese patients) can be factors increasing the complications. A steep learning curve could be an additional factor affecting the complication rate.

US has also been used for investigating the status of the cephalic vein (their dimensions and deepness) [31,38]. This technique can be useful for the diagnosis of an anatomical absence of this vein. In this case, the EJV can be approached surgically [53]. In contrast, in the case of an US diagnosis of a narrow cephalic vein, the approach to this vein is not prohibitive because it can be dilated and cannulated using a mixed technique. No scientific recommendation exists in the literature for cases where it is impossible to use the cephalic vein, but the surgical use of another nearby vein can preserve the patients from complications $[8,52,53]$.

Arterial puncture is particularly related to percutaneous techniques, and this complication can be fatal if associated with haemopneumothorax [56]. This complication is still present, both before and after US technique applications, 
Table 9 Immediate complications that occurred with a pure percutaneous technique by author and type of complication

\begin{tabular}{|c|c|c|c|c|c|c|}
\hline Year & Author & $\begin{array}{l}\text { Percutaneous } \\
\text { technique }\end{array}$ & PNX & HMT & APP & HMM \\
\hline 2010 & Silas [10] & 536 & - & - & - & - \\
\hline 2011 & Knebel [12] & 49 & 2 & - & - & - \\
\hline 2011 & Lin [13] & 113 & 1 & - & 0 & - \\
\hline 2011 & Barbetakis [14] & 700 & 16 & - & 11 & 16 \\
\hline 2012 & Kim [17] & 441 & 2 & - & 11 & 10 \\
\hline 2013 & Osawa [18] & 207 & 3 & & 1 & \\
\hline 2015 & Lin [18] & 29 & 1 & - & - & 1 \\
\hline 2014 & Cavallaro [20] & 143 & 2 & & & 2 \\
\hline 2014 & Cheng [21] & 214 & 0 & - & 0 & - \\
\hline 2014 & Zhou [22] & 492 & - & - & 6 & 12 \\
\hline 2014 & Granziera [23] & 690 & 4 & - & 12 & - \\
\hline 2014 & Seo [25] & 216 & - & - & 2 & - \\
\hline 2015 & Tagliari [26] & 110 & - & - & 6 & 1 \\
\hline 2015 & Gurkan [27] & 324 & 3 & - & 17 & 5 \\
\hline 2015 & An [28] & 397 & - & - & 12 & - \\
\hline 2015 & Wu [29] & 668 & 5 & - & - & - \\
\hline 2016 & Otsubo [31] & 122 & 1 & - & 5 & - \\
\hline 2016 & Zerati [32] & 1202 & 1 & - & 14 & 2 \\
\hline 2016 & Ma [33] & 2996 & 9 & 2 & - & 4 \\
\hline 2017 & Feo [34] & 527 & 3 & - & - & - \\
\hline 2017 & Seo [35] & 932 & - & - & - & - \\
\hline 2018 & Hong [37] & 176 & - & - & - & - \\
\hline 2019 & Hashimoto [38] & 9 & - & - & - & - \\
\hline 2019 & Sun [39] & 55 & 0 & 0 & 1 & - \\
\hline 2019 & $\mathrm{Xu}[40]$ & 67 & - & - & 1 & - \\
\hline 2019 & Sun [41] & 283 & 0 & 0 & 1 & - \\
\hline 2019 & Sun [42] & 619 & 2 & 0 & 5 & 1 \\
\hline 2019 & Velioglu [43] & 2084 & 16 & - & 63 & 27 \\
\hline 2020 & Souadka [44] & 135 & - & - & 6 & 4 \\
\hline \multirow[t]{2}{*}{2021} & Sun [46] & 107 & - & - & 1 & - \\
\hline & & 14,643 & 71 & 2 & 175 & 85 \\
\hline
\end{tabular}

Legend: $P N X$, pneumothorax; $H M T$, haemothorax; $A A P$, accidental arterial puncture; $H M M$, haematomas and can cause a haematoma when the Seldinger technique is applied. This complication can also occur when using a cut-down technique, but in this case, the cause is related to difficult haemostasis for coagulation disorders or a difficult or incorrect dissection, especially in obese patients. In the present review, haematomas, as a complication of surgical cut-down, are presented in a manuscript in which almost all cases were reported. In this manuscript, both the cephalic vein and the external jugular vein were used, but there was no specification about the most frequently involved vein or the cause of the high rate of haematomas. The only factor that can be considered is that the majority of the procedures were performed by residents. However, this cannot be proven to be the cause for sure.

In this review, in contrast to the previous one [53], no mortality was reported. This is due to an ever-greater experience in most institutions with this procedure, preventing this final complication.

\section{Conclusions}

The percutaneous approach is currently the most commonly used technique to implant a TIVAD. Over the years, many methods have been used to decrease immediate complications that can be fatal, such as PNX or haemopneumothorax. Employing US to localize the vein well and to guide vein puncture is the most popular and strongly recommended method. The incidence of PNX has decreased in the last 10 years when US is used for the percutaneous approach, but despite the many efforts, immediate complications are still occurring. Surgical cut-down remains the 
Table 10 Complications in relation to the site of implant

\begin{tabular}{|c|c|c|c|}
\hline Vein & Complications & & \\
\hline \multirow[t]{4}{*}{ CFV 1721} & PNX & - & \\
\hline & HMT & - & \\
\hline & AAP & - & \\
\hline & HMM & 1 & $0.1 \%$ \\
\hline \multirow[t]{4}{*}{ EJV 956} & PNX & - & \\
\hline & HMT & - & \\
\hline & AAP & - & \\
\hline & HMM & 4 & $0.4 \%$ \\
\hline \multirow[t]{4}{*}{ BCV 68} & PNX & - & \\
\hline & HMT & - & \\
\hline & AAP & - & \\
\hline & HMM & - & \\
\hline \multirow[t]{4}{*}{ IJV 5784} & PNX & 2 & $0.03 \%$ \\
\hline & HMT & - & \\
\hline & AAP & 15 & $0.3 \%$ \\
\hline & HMM & 5 & $0.09 \%$ \\
\hline \multirow[t]{4}{*}{ SCV 5321} & PNX & 26 & $0.5 \%$ \\
\hline & HMT & - & \\
\hline & AAP & 68 & $1.3 \%$ \\
\hline & HMM & 29 & $0.5 \%$ \\
\hline \multirow[t]{4}{*}{ AXV 2172} & PNX & 6 & $0.3 \%$ \\
\hline & HMT & - & \\
\hline & AAP & 3 & $0.1 \%$ \\
\hline & HМM & - & \\
\hline \multirow[t]{4}{*}{ INV 744} & PNX & 1 & $0.1 \%$ \\
\hline & HMT & - & \\
\hline & AAP & 5 & $0.7 \%$ \\
\hline & HMM & 1 & $0.1 \%$ \\
\hline \multirow[t]{4}{*}{ BCV 622} & PNX & - & \\
\hline & HMT & - & \\
\hline & AAP & 1 & $0.2 \%$ \\
\hline & HMM & - & \\
\hline
\end{tabular}

Legend: $C F V$, cephalic vein; $E J V$, external jugular vein; $B C V$, brachiocephalic vein; $I J V$, internal jugular vein; $S C V$, subclavian vein; $A X V$, axillary vein; $I N V$, innominate vein

only technique that can avoid all the immediate complications 40 years after the first implant, especially those that can be fatal for the patients.

Author's contributions Study conception and design: Di Carlo I. Acquisition of data: Fontana EG and Schembari E. Analysis and interpretation of data: Di Carlo I and Toro A. Drafting of manuscript: Toro A. Critical revision of manuscript: Di Carlo I and Di Saverio S.

Funding Open access funding provided by Università degli Studi di Catania within the CRUI-CARE Agreement.
Data availability Not applicable.

Code availability Not applicable.

\section{Declarations}

Ethics approval Not applicable.

Consent to participate Not applicable.

Consent for publication Not applicable.

Additional declarations for articles in life science journals that report the results of studies involving humans and/or animals Not applicable.

Competing interests The authors declare no competing interests.

Open Access This article is licensed under a Creative Commons Attribution 4.0 International License, which permits use, sharing, adaptation, distribution and reproduction in any medium or format, as long as you give appropriate credit to the original author(s) and the source, provide a link to the Creative Commons licence, and indicate if changes were made. The images or other third party material in this article are included in the article's Creative Commons licence, unless indicated otherwise in a credit line to the material. If material is not included in the article's Creative Commons licence and your intended use is not permitted by statutory regulation or exceeds the permitted use, you will need to obtain permission directly from the copyright holder. To view a copy of this licence, visit http://creativecommons.org/licenses/by/4.0/.

\section{References}

1. Di Carlo I, Biffi R (2012) Totally implantable venous access devices. Ed. Springer-Verlag, Italia S.r.1. p 1-286

2. Seldinger SI (1953) Catheter replacement of the needle in percutaneous arteriography: a new technique. Acta Radiol 39:368-376. https://doi.org/10.3109/00016925309136722

3. Niederhuber JE, Ensminger W, Gyves JW, Liepman M, Doan K, Cozzi E (1982) Totally implanted venous and arterial access system to replace external catheters in cancer treatment. Surgery 92:706-712

4. Tabatabaie O, Kasumova GG, Eskander MF, Critchlow JF, Tawa NE, Tseng JF (2017) Totally implantable venous access devices: a review of complications and management strategies. Am J Clin Oncol 40:94-105. https://doi.org/10.1097/COC.0000000000 000361

5. Goltz JP, Petritsch B, Kirchner J, Hahn D, Kickuth R (2013) Percutaneous image-guided implantation of totally implantable venous access ports in the forearm or the chest? A patients' point of view. Support Care Cancer 21:505-510. https://doi.org/10. 1007/s00520-012-1544-2

6. Biffi R, Pozzi S, Bonomo G, Della Vigna P, Monfardini L, Radice D, Rotmensz N, Zampino MG, Fazio N, Orsi F (2014) Cost effectiveness of different central venous approaches for port placement and use in adult oncology patients: evidence from a randomized three-arm trial. Ann Surg Oncol 21:3725-3731. https://doi.org/ 10.1245/s10434-014-3784-5

7. Burbridge B, Goyal K (2016) Quality-of-life assessment: arm TIVAD versus chest TIVAD. J Vasc Access 17:527-534. https:// doi.org/10.5301/jva.5000609 
8. Di Carlo I, Pulvirenti E, Mannino M, Toro A (2010) Increased use of percutaneous technique for totally implantable venous access devices. Is it real progress? A 27-year comprehensive review on early complications. Ann Surg Oncol 17:1649-1656. https://doi. org/10.1245/s10434-010-1005-4

9. Liberati A, Altman DG, Tetzlaff J, Mulrow C, Gøtzsche PC, Ioannidis JP, Clarke M, Devereaux PJ, Kleijnen J, Moher D (2009) The PRISMA statement for reporting systematic reviews and meta-analyses of studies that evaluate healthcare interventions: explanation and elaboration. BMJ 339:b2700. https://doi.org/10. 1136/bmj.b2700

10. Silas AM, Perrich KD, Hoffer EK, McNulty NJ (2010) Complication rates and outcomes of 536 implanted subcutaneous chest ports: do rates differ based on the primary operator's level of training? Acad Radiol 17:464-467. https://doi.org/10.1016/j.acra. 2009.10.019

11. Koketsu S, Samesima S, Yoneyama S, Okada T, Tomozawa S, Horikoshi H, Sawada T (2010) Outcome of cephalic vein cutdown approach: a safe and feasible approach for totally implantable venous access device placement. Oncol Lett 1:1029-1031. https://doi.org/10.3892/ol.2010.189

12. Knebel P, Lopez-Benitez R, Fischer L, Radeleff BA, Stampfl U, Bruckner T, Hennes R, Kieser M, Kauczor HU, Büchler MW, Seiler CM (2011) Insertion of totally implantable venous access devices: an expertise-based, randomized, controlled trial (NCT00600444). Ann Surg 253:1111-1117. https://doi.org/10. 1097/SLA.0b013e318214ba21

13. Lin YC, Chu CH, Ou KW, Chan DC, Hsieh CB, Chen TW, Hsu HM, Yu JC (2011) Use of a totally implantable access port through the external jugular vein when the cephalic vein approach is not feasible. Ann Vasc Surg 25:217-221. https:// doi.org/10.1016/j.avsg.2010.07.017

14. Barbetakis N, Asteriou C, Kleontas A, Tsilikas C (2011) Totally implantable central venous access ports. Analysis of 700 cases. J Surg Oncol 104:654-656. https://doi.org/10.1002/jso.21990

15. Di Carlo I, Toro A, Pulvirenti E, Palermo F, Scibilia G, Cordio S (2011) Could antibiotic prophylaxis be not necessary to implant totally implantable venous access devices? Randomized prospective study. Surg Oncol 20:20-25. https://doi.org/10.1016/j. suronc.2009.09.003

16. Narducci F, Jean-Laurent M, Boulanger L, El Bédoui S, Mallet Y, Houpeau JL, Hamdani A, Penel N, Fournier C (2011) Totally implantable venous access port systems and risk factors for complications: a one-year prospective study in a cancer centre. Eur J Surg Oncol 37:913-918. https://doi.org/10.1016/j. ejso.2011.06.016

17. Kim JT, Oh TY, Chang WH, Jeong YK (2012) Clinical review and analysis of complications of totally implantable venous access devices for chemotherapy. Med Oncol 29:1361-1364. https://doi.org/10.1007/s12032-011-9887-y

18. Osawa H, Hasegawa J, Yamakawa K, Matsunami N, Mikata S, Shimizu J, Kim YK, Morishima H, Hirota M, Souma Y, Kim HM, Sawada G, Nezu R (2013) Ultrasound-guided infraclavicular axillary vein puncture is effective to avoid pinch-off syndrome: a long-term follow-up study. Surg Today 43:745-750. https://doi.org/10.1007/s00595-012-0309-3

19. Lin $\mathrm{CH}, \mathrm{Yu}$ JC, Lee YT, Wu HS (2013) Conversion from cephalic vein to external jugular vein: success rate increased on totally implantable access ports with cut-down method. Surg Innov 20:566-569. https://doi.org/10.1177/1553350613479178

20. Cavallaro G, Sanguinetti A, Iorio O, D'Ermo G, Polistena A, Avenia N, Silecchia G, De Toma G (2014) Ultrasound-guided vein puncture versus surgical cut-down technique in totally implantable venous access devices (TIVADS): a prospective comparative study on safety, efficacy and complications.
Int Surg 99:475-478. https://doi.org/10.9738/INTSU RG-D-14-00008.1

21. Cheng HW, Ting CK, Chu YC, Chang WK, Chan KH, Chen PT (2014) Application of an ultrasound-guided low-approach insertion technique in three types of totally implantable access port. J Chin Med Assoc 77:246-252. https://doi.org/10.1016/j.jcma. 2014.02.005

22. Zhou J, Qian S, He W, Han G, Li H, Luo R (2014) Implanting totally implantable venous access port via the internal jugular vein guided by ultrasonography is feasible and safe in patients with breast cancer. World J Surg Oncol 12:378. https://doi.org/ 10.1186/1477-7819-12-378

23. Granziera E, Scarpa M, Ciccarese A, Filip B, Cagol M, Manfredi V, Alfieri R, Celentano C, Cappellato S, Castoro C, Meroni M (2014) Totally implantable venous access devices: retrospective analysis of different insertion techniques and predictors of complications in 796 devices implanted in a single institution. BMC Surg 14:27. https://doi.org/10.1186/1471-2482-14-27

24. Cavallaro G, Iorio O, Iossa A, Rizzello M, Silecchia G, De Toma G (2014) Surgical approach for totally implantable venous access devices: consideration after 753 consecutive procedures. Am Surg 80:513-515. https://doi.org/10.1177/000313481408000526

25. Seo TS, Song MG, Kang EY, Lee CH, Yong HS, Doo K (2014) A single-incision technique for placement of implantable venous access ports via the axillary vein. J Vasc Interv Radiol 25:14391446. https://doi.org/10.1016/j.jvir.2013.12.571

26. Tagliari AP, Staub FL, Guimarães JR, Migliavacca A, MossmannDda F (2015) Evaluation of three different techniques for insertion of totally implantable venous access device: a randomized clinical trial. J Surg Oncol 112:56-59. https://doi.org/10. $1002 /$ jso. 23962

27. Gurkan S, Seber S, Gur O, Yetisyigit T, OkanDonbaloglu M, Ozkaramanli Gur D (2015) Retrospective evaluation of totally implantable venous access port devices: early and late complications. J BUON 20:338-345

28. An H, Ryu CG, Jung EJ, Kang HJ, Paik JH, Yang JH, Hwang DY (2015) Insertion of totally implantable central venous access devices by surgeons. Ann Coloproctol 31:63-67. https://doi.org/ 10.3393/ac.2015.31.2.63

29. Wu CY, Lin FS, Wang YC, Chou WH, Lin WY, Sun WZ, Lin CP (2015) Fast Track ultrasound protocol to detect acute complications after totally implantable venous access device placement. Ann Surg Oncol 22:1943-1949. https://doi.org/10.1245/ s10434-014-4222-4

30. Cavallaro G, Iorio O, Iossa A, De Angelis F, Avallone M, Massaro M, Mattia C, Silecchia G (2015) A prospective evaluation on external jugular vein cut-down approach for TIVAD implantation. World J Surg Oncol 13:243. https://doi.org/10.1186/ s12957-015-0663-X

31. Otsubo R, Hatachi T, Shibata K, Yoshida T, Watanabe H, Oikawa M, Matsumoto M, Yano H, Taniguchi H, Nagayasu T (2016) Evaluation of totally implantable central venous access devices with the cephalic vein cut-down approach: usefulness of preoperative ultrasonography. J Surg Oncol 113:114-119. https://doi.org/10. $1002 /$ jso. 24100

32. Zerati AE, Figueredo TR, de Moraes RD, da Cruz AM, da MottaLeal Filho JM, Freire MP, Wolosker N, de Luccia N (2016) Risk factors for infectious and noninfectious complications of totally implantable venous catheters in cancer patients. J Vasc Surg Venous Lymphat Disord 4:200-205. https://doi.org/10.1016/j. jvsv.2015.10.008

33. Ma LI, Liu Y, Wang J, Chang Y, Yu L, Geng C (2016) Totally implantable venous access port systems and associated complications: a single-institution retrospective analysis of 2,996 breast cancer patients. Mol Clin Oncol 4:456-460. https://doi.org/10. $3892 /$ mco. 2016.726 
34. Feo CF, Ginesu GC, Bellini A, Cherchi G, Scanu AM, Cossu ML, Fancellu A, Porcu A (2017) Cost and morbidity analysis of chest port insertion in adults: outpatient clinic versus operating room placement. Ann Med Surg (Lond) 21:81-84. https://doi.org/10. 1016/j.amsu.2017.07.056

35. Seo TS, Song MG, Kim JS, Choi CW, Seo JH, Oh SC, Kang EJ, Lee JK, Lee SY (2017) Long-term clinical outcomes of the singleincision technique for implantation of implantable venous access ports via the axillary vein. J Vasc Access 18:345-351. https://doi. org/10.5301/jva.5000751

36. Kagawa T, Ueyama S, Kobayashi T, Okabayashi H, Kuroda $\mathrm{S}$, Fujiwara T (2017) A novel "shrug technique" for totally implantable venous access devices via the external jugular vein: A consecutive series of 254 patients. J Surg Oncol 115:291-295. https:// doi.org/10.1002/jso. 24504

37. Hong S, Seo TS, Song MG, Seol HY, Suh SI, Ryoo IS (2019) Clinical outcomes of totally implantable venous access port placement via the axillary vein in patients with head and neck malignancy. J Vasc Access 20:134-139. https://doi.org/10.1177/11297 29818781270

38. Hashimoto S, Otsubo R, Adachi M, Doi R, Shibata K, Sano I, Shibata Y, Nakazaki T, Taniguchi H, Nagayasu T (2019) Cephalic vein cut-down for totally implantable central venous access devices with preoperative ultrasonography by surgical residents. In Vivo 33:2079-2085. https://doi.org/10.21873/invivo.11707

39. Sun X, Zhang Y, Yang C, Zhou Y, Bai X, Zheng W, Jin Y (2019) Ultrasound-guided totally implantable venous access device through the right innominate vein in older patients is safe and reliable. Geriatr Gerontol Int 19:218-221. https://doi.org/10.1111/ ggi.13611

40. Xu L, Qin W, Zheng W, Sun X (2019) Ultrasound-guided totally implantable venous access ports via the right innominate vein: a new approach for patients with breast cancer. World J Surg Oncol 17:196. https://doi.org/10.1186/s12957-019-1727-0

41. Sun X, Xu J, Xia R, Wang C, Yu Z, Zhang J, Bai X, Jin Y (2019) Efficacy and safety of ultrasound-guided totally implantable venous access ports via the right innominate vein in adult patients with cancer: single-centre experience and protocol. Eur J Surg Oncol 45:275-278. https://doi.org/10.1016/j.ejso.2018.07.048

42. Sun X, Bai X, Shen J, Yu Z, Zhuang Z, Jin Y (2019) Comparison between ultrasound-guided TIVAD via the right innominate vein and the right internal jugular vein approach. BMC Surg 19:189. https://doi.org/10.1186/s12893-019-0651-0

43. Velioğlu Y, Yüksel A, Sınmaz E (2019) Complications and management strategies of totally implantable venous access port insertion through. Turk Gogus Kalp Damar Cerrahisi Derg 27:499_ 507. https://doi.org/10.5606/tgkdc.dergisi.2019.17972

44. Souadka A, Essangri H, Boualaoui I, Ghannam A, Benkabbou A, Amrani L, Mohsine R, Majbar MA (2020) Supraclavicular versus infraclavicular approach in inserting totally implantable central venous access for cancer therapy: a comparative retrospective study. PLoS One 5:e0242727. https://doi.org/10.1371/journ al.pone.0242727.eCollection

45. Mehta N, Desai SM, Dhakad V, Patel D, Saldanha E (2020) External jugular cutdown technique for totally implantable venous access devices: a single-centre study. Indian J Surg Oncol 11:418-422. https://doi.org/10.1007/s13193-020-01103-9

46. Sun X, Bai X, Zhang Y, Xu L, Yu Z, Jin Y, Zhuang Z (2021) Perioperative and postoperative complications of ultrasoundguided totally implantable venous access ports via the brachiocephalic vein in patients with cancer: a prospective study. J Cancer 12:1379-1385. https://doi.org/10.7150/jca.55343.eCollection

47. Di Carlo I, Cordio S, La Greca G, Privitera G, Russello D, Puleo S, Latteri F (2001) Totally implantable venous access devices implanted surgically: a retrospective study on early and late complications. Arch Surg 136:1050-1053. https://doi.org/10.1001/ archsurg.136.9.1050

48. Di Carlo I, Toro A (2017) The totally implantable venous access device with occurrence of pneumothorax still remains an issue. World J Surg 41:1398. https://doi.org/10.1007/s00268-016-3850-1

49. Marcy PY, Schiappa R, Ferrero JM, Dahlet C, Brenet O, Yazbec G, Dubois PY, Salm B, Fouche Y, Mari V, Montastruc M, Lebrec N, Ancel B, Paillocher N, Dupoiron D, Rangeard O, Gal J, Ettaiche M, Chateau Y, Chamorey E (2017) Patient satisfaction and acceptance of their totally implanted central venous catheter: a French prospective multicenter study. J Vasc Access 18:390-395. https://doi.org/10.5301/jva.5000744

50. Knebel P, Fischer L, Huesing J, Hennes R, Büchler MW, Seiler CM (2009) Randomized clinical trial of a modified Seldinger technique for open central venous cannulation for implantable access devices. Br J Surg 96:159-165. https://doi.org/10.1002/ bjs. 6457

51. Hüttner FJ, Bruckner T, Hackbusch M, Weitz J, Bork U, Kotschenreuther P, Heupel O, Kümmel S, Schlitt HJ, Mattulat M, Pintér L, Seiler CM, Gutt CN, Nottberg HS, Pohl A, Ghanem F, Meyer T, Imdahl A, Neudecker J, Müller VA, Gehrig T, Reineke M, von Frankenberg M, Schumacher G, Hennes R, Mihaljevic AL, Rossion I, Klose C, Kieser M, Büchler MW, Diener MK, Knebel P (2020) Primary open versus closed implantation strategy for totally implantable venous access ports: the multicentre randomized controlled PORTAS-3 Trial (DRKS 00004900). Ann Surg 272:950-960. https://doi.org/10.1097/SLA.0000000000003705

52. Di Carlo I, Puleo S (2001) A new technique for insertion of totally implantable venous access devices (TIVAD). Surgery 129:768769. https://doi.org/10.1067/msy.2001.115351

53. Di Carlo I, Barbagallo F, Toro A, Sofia M, Lombardo R, Cordio S (2005) External jugular vein cutdown approach, as a useful alternative, supports the choice of the cephalic vein for totally implantable access device placement. Ann Surg Oncol 12:570573. https://doi.org/10.1245/ASO.2005.04.028

54. Becker F, Wurche LA, Darscht M, PascherA, Struecker B (2021) Totally implantable venous access port insertion via open Seldinger approach of the internal jugular vein-a retrospective risk stratification of 500 consecutive patients. Langenbecks Arch Surg. https://doi.org/10.1007/s00423-021-02097-w

55. TumayLV, Guner OS (2020) Availability of totally implantable venous access devices in cancer patients is high in the long term: a seven-year follow-up study.Support Care Cancer.https://doi.org/ 10.1007/s00520-020-05871-6

56. Nicholson T, Ettles D, Robinson G (2004) Managing inadvertent arterial catheterization during central venous access procedures. Cardiovasc Intervent Radiol 27:21-25. https://doi.org/10.1007/ s00270-003-0043-8

57. Taxbro K, Hammarskjöld F, Juhlin D, Hagman H, Bernfort L, Berg S (2020) Cost analysis comparison between peripherally inserted central catheters and implanted chest ports in patients with cancer-a health economic evaluation of the PICCPORT trial. Acta Anaesthesiol Scand 64:385-393. https://doi.org/10.1111/aas. 13505

Publisher's Note Springer Nature remains neutral with regard to jurisdictional claims in published maps and institutional affiliations. 